\title{
Adiponectin receptors are expressed in hypothalamus and colocalized with proopiomelanocortin and neuropeptide $Y$ in rodent arcuate neurons
}

\author{
E Guillod-Maximin*, A F Roy*, C M Vacher, A Aubourg, V Bailleux, A Lorsignol ${ }^{1}$, L Pénicaud ${ }^{1}$, M Parquet \\ and $\mathbf{M}$ Taouis
}

UMR 1197, Université Paris-Sud 11/INRA, NMPA, Bat 447, 91405 Orsay Cedex, France

${ }^{1}$ UMR 5241 CNRS-UPS, BP 84225, 31432 Toulouse Cedex 4, France

(Correspondence should be addressed to M Parquet; Email: michel.parquet@u-psud.fr)

*(E Guillod-Maximin and A F Roy equally contribute to this work)

\begin{abstract}
Adiponectin is involved in the control of energy homeostasis in peripheral tissues through Adipor1 and Adipor2 receptors. An increasing amount of evidence suggests that this adipocytesecreted hormone may also act at the hypothalamic level to control energy homeostasis. In the present study, we observed the gene and protein expressions of Adipor1 and Adipor2 in rat hypothalamus using different approaches. By immunohistochemistry, Adipor1 expression was ubiquitous in the rat brain. By contrast, Adipor2 expression was more limited to specific brain areas such as hypothalamus, cortex, and hippocampus. In arcuate and paraventricular hypothalamic nuclei, Adipor1, and Adipor2 were expressed by neurons and astrocytes. Furthermore, using transgenic green fluorescent protein mice, we
\end{abstract}

showed that Adipor1 and Adipor2 were present in proopiomelanocortin (POMC) and neuropeptide Y (NPY) neurons in the arcuate nucleus. Finally, adiponectin treatment by intracerebroventricular injection induced AMP-activated protein kinase (AMPK) phosphorylation in the rat hypothalamus. This was confirmed by in vitro studies using hypothalamic membrane fractions. In conclusion, Adipor1 and Adipor2 are both expressed by neurons (including POMC and NPY neurons) and astrocytes in the rat hypothalamic nuclei. Adiponectin is able to increase AMPK phosphorylation in the rat hypothalamus. These data reinforced a potential role of adiponectin and its hypothalamic receptors in the control of energy homeostasis.

Journal of Endocrinology (2009) 200, 93-105

\section{Introduction}

Adiponectin, a hormone secreted by adipose tissue, plays a key role in the control of energy homeostasis through the regulation of glucose and fatty acids metabolism in peripheral tissues such as muscle and liver (Berg et al. 2002). Due to its effects, adiponectin is described as an anti-diabetic and anti-atherogenic adipokine (Gil-Campos et al. 2004). It acts through two receptors: Adipor1 and Adipor2 (Yamauchi et al. 2003, 2007). Adiponectin receptors were localized in various peripheral tissues (Kharroubi et al. 2003, Berner et al. 2004, Ding et al. 2004, Kadowaki \& Yamauchi 2005, Pineiro et al. 2005, Dai et al. 2006, Kadowaki et al. 2008). However, Adipor1 is more abundantly expressed in muscles while Adipor2 predominates in the liver (Yamauchi et al. 2003). Recently, they have also been described in rodent and human hypothalamus (Kos et al. 2007, Kubota et al. 2007, Coope et al. 2008). These receptors present seven transmembrane domains with an intracellular N-terminus and an extracellular C-terminus predicting that they are functionally and structurally distinct from the known $G$ protein-coupled receptors (Kadowaki \& Yamauchi 2005). The cellular signaling cascade resulting from the interaction of adiponectin with its receptors is not yet well understood. Adiponectin binding to AdipoRs leads to the activation of AMP-activated protein kinase (AMPK), peroxisome proliferator-activated receptor $\alpha(\operatorname{PPAR} \alpha)$, fatty acid oxidation and glucose uptake (Long \& Zierath 2006, Yoon et al. 2006). Recently, several components of AdipoRs signaling pathways were identified such as adaptor protein containing pleckstrin homology domain, phosphotyrosine-binding (PTB) domain and leucine-zipper motif (APPL1), which associates to Adipor1 in muscle cells through a PTB domain (Mao et al. 2006). This interaction does not require Adipor1 phosphorylation. APPL1 may then initiate downstream signaling through the kinase LKB1, which phosphorylates on threonine residue and thus activates AMPK (Yamauchi et al. 2002, Hawley et al. 2003). It is noteworthy that the direct interaction between APPL1 and LKB/AMPK needs to be elucidated. In peripheral tissues, activated AMPK controls several metabolic processes: stimulation of fatty acid oxidation and glucose uptake as well as inhibition of glycogen and fatty acids synthesis (Carling 2005). Beside these peripheral metabolic effects, recent reports indicate that hypothalamic AMPK is probably involved in the control of 
food intake, as this kinase is inhibited by anorexigenic leptin and insulin, and conversely stimulated by orexigenic ghrelin (Andersson et al. 2004, Minokoshi et al. 2004, Kim \& Lee 2005). In the hypothalamus, AMPK activity is negatively correlated with malonyl-CoA content whose hypothalamic accumulation inhibits food intake (Hu et al. 2003, Lane et al. 2005, Wolf 2006). Moreover, adiponectin intracerebroventricular (ICV) treatment of mice led to weight loss through increased energy expenditure (Qi et al. 2004). Taken together, these data indicate that adiponectin may signal in the hypothalamus through the modulation of AMPK activity, leading to energy homeostasis control.

In the present study, we attempted to characterize AdipoRs in rat hypothalamus by combining biochemical, molecular, and immunohistochemical approaches. We report that Adipor1 and Adipor2 are expressed in the rat hypothalamus and interestingly in areas involved in the control of food intake such as the arcuate nucleus. Using, homozygous transgenic pro-opiomelanocortin (POMC) and neuropeptide Y (NPY)-green fluorescent protein (GFP) mice we demonstrate the expression of Adipor1/Adipor2 in POMC and NPY neurons. Finally, we show that acute adiponectin ICV injection significantly increased hypothalamic AMPK phosphorylation.

\section{Materials and Methods}

\section{Animals}

Adult male Wistar rats obtained from Janvier Laboratory (Le Genest Saint Isle, France) were housed in our breeding unit and maintained under a 14h light:10h darkness cycle (lights on $1900 \mathrm{~h}$ ), with free access to food and water.

Homozygous transgenic POMC- or NPY-GFP mice provided by Dr Friedman (Rockefeller University, New York, NY, USA) were used in some experiments. These lines of transgenic mice were generated by using bacterial artificial chromosome expressing topaz GFP under the transcriptional control of POMC genomic sequence or sapphire GFP under the transcriptional control of NPY genomic sequences (POMCGFP and NPY-GFP mice respectively; Pinto et al. 2004).

Animal studies were carried out in agreement with the European legislation on animal experimentation and with the authorization of the French Ministry of Agriculture.

\section{RT-PCR analysis}

Total RNA from rat hypothalamus was extracted using Insta Pure Kit (Eurogentec, Seraing, Belgium) according to manufacturer's recommendations. A $1 \mu \mathrm{g}$ portion of the total denatured was reverse transcribed with $50 \mathrm{U}$ of Moloney murine leukemia virus reverse transcriptase (Ozyme, Saint Quentin en Yvelines, France) in the presence of a mixture of random and Oligo dT primers (Invitrogen) as previously described (Benomar et al. 2006). The resulting cDNAs were submitted to PCR for 30 cycles. As control, RT products were omitted. The PCR primers were chosen from GeneBank database (Adipor1:gi46485455; Adipor2:gi83816890), we have used as control the amplification of ribosomic 18S RNA and were as follows:

\section{Adipor1 sens: 5'AGGAGTTCGTATATAAGGTCTG3';} Adipor1 antisense: ${ }^{\prime}$ ACATATTTGGTCTGAGCATGGT3';

Adipor2 sens: 5'ACGAATGGAAGAGTTTGTTTG3'; Adipor2 antisense: 5'GGCGAAACATATAAAAGATCC3'.

18S RNA sens: $5^{\prime}$ CGGCAAAGTGAAGATTGGAG $3^{\prime}$ 18S RNA antisense: $5^{\prime}$ CCGTGTTTACAGATGTAGTCGAAC $3^{\prime}$.

Adipor1 primers flank a region of $243 \mathrm{bp}$, Adipor2 primers flank a region of $242 \mathrm{bp}$ and $18 \mathrm{~S}$ RNA primers a region of $107 \mathrm{bp}$.

Amplified Adipor1 and Adipor2 cDNA fragments were cloned using TOPO TA cloning Kit (Invitrogen) and sequenced (Genome Express, Meylan, France). Obtained sequences were analyzed through NCBI data bank.

\section{Adiponectin ICV treatment of rats}

Rats (290-310 g) were anesthetized by an i.p. injection of ketamine $(100 \mathrm{mg} / \mathrm{kg}$ body weight $)$ and xylazine $(10 \mathrm{mg} / \mathrm{kg}$; Centravet, Lapallise, France) and implanted stereotaxically into the third ventricle $(7.7 \mathrm{~mm}$ anterior to the interaural line and $8 \mathrm{~mm}$ in depth from skull; Paxinos \& Watson 2005) with 24-gauge stainless steel guide cannula using the DKI-900 Kopf stereotaxic apparatus (PHYMEP, Paris, France). Animals were allowed to recover for one week before ICV injections. Following anesthesia, rats were treated either with placebo (30 mM Tris $\mathrm{pH} 8 \cdot 5, n=3$ ) or globular adiponectin (Human recombinant adiponectin, Axxora, San Diego, CA, USA; $0.5 \mu \mathrm{g} / \mathrm{rat}, n=4)$. Thirty minutes later, animals were sacrificed by decapitation after cervical elongation and hypothalami quickly removed and frozen.

\section{Western blot analysis}

Western blot analyses were performed as previously described (Benomar et al. 2005, Ferezou-Viala et al. 2007). Briefly, frozen hypothalami were homogenized in lysis buffer $(10 \mathrm{mM}$ Tris$\mathrm{HCl}$ (pH 7.5), $150 \mathrm{mM} \mathrm{NaCl}, 1$ mM EGTA, 1 mM EDTA, 1\% nonidet-P40, 1\% Triton X-100, protease inhibitor cocktail $(0.35 \mathrm{mg} / \mathrm{ml}$ phenylmethylsulphonyl fluoride (PMSF), $2 \mu \mathrm{g} / \mathrm{ml}$ leupeptin, $2 \mu \mathrm{g} / \mathrm{ml}$ aprotinin), and phosphatase inhibitor cocktail (10 mM sodium fluoride, $1 \mathrm{mM}$ sodium orthovanadate, $20 \mathrm{mM}$ sodium $\beta$-glycerophosphate, $10 \mathrm{mM}$ benzamidine)). After lysis on ice for $90 \mathrm{~min}$, insoluble materials were removed by centrifugation (15 000 r.p.m. at $4{ }^{\circ} \mathrm{C}$ for $45 \mathrm{~min}$ ) and protein concentrations of the resulting lysates were determined using a protein assay kit BCA (Pierce, Perbio Science, France). Proteins $(100 \mu \mathrm{g})$ were subjected to SDS-PAGE and transferred onto 
nitrocellulose membranes. Blots were blocked with 5\% non-fat milk and then incubated in the presence of appropriate primary antibodies: anti-Adipor1 and antiAdipor2 rabbit antibodies respectively directed against the 357-375 and 374-386 sequence of the human protein that is highly conserved in rats and in addition all quality control of these antibodies were performed in rat tissues by Phoenix Pharmaceuticals Laboratories (Karlsruhe, Germany), anti-phospho-AMPK (p-AMPK), anti-total-AMPK (t-AMPK) or anti- $\beta$-tubulin rabbit antibodies (Cell Signaling, Saint-Quentin-en-Yvelines, France), and appropriate secondary antibodies. Following nitrocellulose membrane washing, targeted proteins were revealed using enhanced chemiluminescent reagents (Amersham Life Science). The intensity of bands was quantified using Bio-1D Software (Vilver Lourmat, Marne-la-Vallée, France) and normalized to t-AMPK for p-AMPK. The p-AMPK/t-AMPK ratios where calculated.

\section{In vitro phosphorylation assays for $A M P K$}

In vitro phosphorylation was performed on hypothalamic total membranes prepared separately from three Wistar rats. Briefly, rat hypothalamus was homogenized in ice-cold homogenization buffer (0.32 $\mathrm{M}$ sucrose; $2 \mathrm{mM}$ EDTA; $2 \mathrm{mM}$ EGTA; $20 \mathrm{mM}$ HEPES; protease inhibitor cocktail $(0.35 \mathrm{mg} / \mathrm{ml}$ PMSF, $2 \mu \mathrm{g} / \mathrm{ml}$ leupeptin, $2 \mu \mathrm{g} / \mathrm{ml}$ aprotinin) and phosphatase inhibitor cocktail $(10 \mathrm{mM}$ sodium fluoride, $1 \mathrm{mM}$ sodium orthovanadate, $20 \mathrm{mM}$ sodium $\beta$-glycerophosphate, $10 \mathrm{mM}$ benzamidine)) and centrifuged for $10 \mathrm{~min}$ at $600 \mathrm{~g}$ at $4{ }^{\circ} \mathrm{C}$. Resulting supernatant containing total membrane fraction was saved and protein content determined as described previously.
In vitro phosphorylation of AMPK was performed as previously described for insulin receptor phosphorylation (Zhao et al. 1999) with the following modifications. Briefly, $50 \mu \mathrm{g}$ of hypothalamic total membrane proteins were diluted with reaction buffer $(50 \mathrm{mM}$ Tris- $\mathrm{HCl}, \mathrm{pH} 7 \cdot 4 ; 1 \mathrm{mM}$ $\mathrm{MgCl} 2 ; 2 \mathrm{mM}$ EGTA; protease inhibitor cocktail as described above). In vitro phosphorylation was stimulated in the presence of $2 \mu \mathrm{g}$ adiponectin and $5 \mathrm{mM}$ ATP; and basal levels of phosphorylation were measured in samples in the absence of adiponectin. Samples were incubated for $20 \mathrm{~min}$ at $37^{\circ} \mathrm{C}$. SDS-PAGE sample buffer was quickly added; samples were boiled for $5 \mathrm{~min}$ and then subjected to SDS-PAGE gel and western blot as described previously.

\section{Tissue preparation for immunohistochemistry}

Three Wistar rats (290-310 g), 5 POMC-GFP and 5 NPYGFP mice were anesthetized by i.p. injection of pentobarbital $(60 \mathrm{mg} / \mathrm{kg}$ of body weight; Ceva Santé Animale, Libourne France) and transcardially perfused with PBS (PBS; pH 7•4) followed by $4 \%$ formaldehyde using a peristaltic pump. Brains were removed and conserved in the same fixative solution at $4{ }^{\circ} \mathrm{C}$. The hypothalamus was cut into $50 \mu \mathrm{m}$ serial sections with a Vibroslicer (1000Plus, Harvard Apparatus, Holliston, MA, USA) and free-floating sections were collected in PBS.

\section{Immunohistochemistry}

After quenching peroxidase activity with $0 \cdot 3 \% \mathrm{H}_{2} \mathrm{O}_{2}$ for $30 \mathrm{~min}$, sections were blocked by $3 \%$ normal goat serum

\section{A}
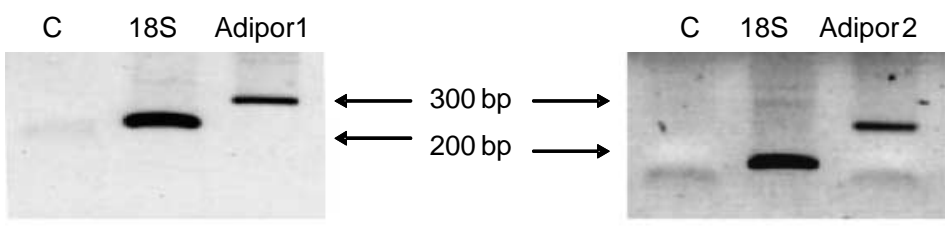

B
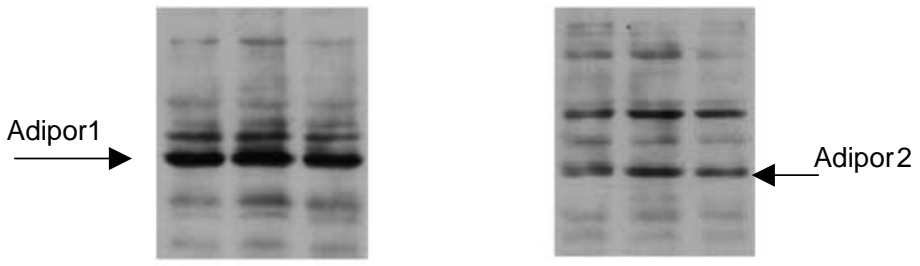

$\beta$-Tubulin

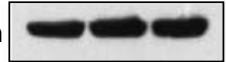

$\beta$-Tubulin

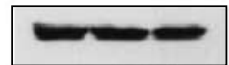

Figure 1 Characterization of rat hypothalamic Adipor1 and Adipor2. (A) Total hypothalamic RNA were subjected to RT-PCR using specific primers toward Adipor1, Adipor2, and ribosomic 18S RNA. Two bands corresponding to Adipor1 (243 bp) and Adipor2 (242 bp) were identified in ethidium bromide-stained agarose gel with the expected size; and a band of 107 bp corresponding to the amplified fragment of 18S RNA. No band was amplified when RT product was omitted (lane C). (B) Total hypothalamic protein lysates were subjected to SDS-PAGE and western blot analysis using specific antibodies revealed Adipor1 (42 kDa) and Adipor2 (44 kDa), and $\beta$-tubulin ( $55 \mathrm{kDa}$ ) was used to normalize protein loading. 
(Sigma)-PBS-0 $25 \%$ triton X100 for $2 \mathrm{~h}$ at room temperature. Sections were then incubated in the presence of anti-Adipor1 or anti- Adipor2 antibody (1:2000 diluted in the same blocking solution) for $16 \mathrm{~h}$ at $4{ }^{\circ} \mathrm{C}$. After washing, sections were incubated with biotinylated goat anti-rabbit IgG (1:1000; Jackson Laboratories, West Grove, PA, USA) for $1 \mathrm{~h}$ at room temperature and finally incubated in peroxidase-conjugated streptavidin (1:1000; Beckman Coulter, Marseille, France) for $1 \mathrm{~h}$ at room temperature. Specificity of labeling was ascertained with omission of primary antibody or by using blocking peptides for each brain. Peroxidase activity was revealed using diaminobenzidine and nickel chloride method (DAB substrate kit for peroxidase, Vector Laboratories, Burlingame, CA, USA). Sections were mounted on slides, air dried, coverslipped with permanent mounting media (Dakocytomation, Carpinteria, CA, USA), and examined under a transmitted-light microscope (Olympus, Rungis, France).

\section{Multiple fluorescence immunohistochemistry}

To determine the cell types expressing the adiponectin receptors, hypothalamic sections were subjected to multiple immunohistochemistries (IHCs) for a neuronal nuclei (NeuN), a glial marker glial fibrillary acidic protein (GFAP) or a presynaptic marker (synaptophysin). After quenching autofluorescence with $50 \mathrm{mM} \mathrm{NH} \mathrm{NH}_{4}$ for $20 \mathrm{~min}$, sections were blocked in the presence of 3\% normal donkey serum (Sigma)-PBS-0.25\% triton $\mathrm{X} 100-0 \cdot 3 \%$ fish gelatin for $2 \mathrm{~h}$ at room temperature, and then anti-Adipor1 or Adipor2 antibody was applied (1:1000) during $16 \mathrm{~h}$ at $4{ }^{\circ} \mathrm{C}$. After washing, free-floating sections were incubated with FluoProbes 488-conjugated donkey anti-rabbit antibody (1:500; Interchim, Montluçon, France) for $1 \mathrm{~h}$ at room temperature and then monoclonal antibodies were added for $1 \mathrm{~h}$ at room temperature in the case of GFAP (1:500; Sigma) and overnight at $4{ }^{\circ} \mathrm{C}$ for $\mathrm{NeuN}(1: 100$; Chemicon Millipore, Temecula, CA, USA) or synaptophysin (1:1000; Sigma). Finally, sections were incubated with Cy3- or Cy5-conjugated donkey anti-mouse (1:500; Jackson Laboratories). Specificity of labeling was ascertained with omission of primary antibodies on one section for each brain or by incubating some sections with the specific blocking peptides. Sections were mounted on slides, coverslipped with anti-fading mounting media (Vectashield, Vector Laboratories), and examined under a laser confocal microscope (argon-krypton laser; Zeiss MRC 1024ES; Zeiss
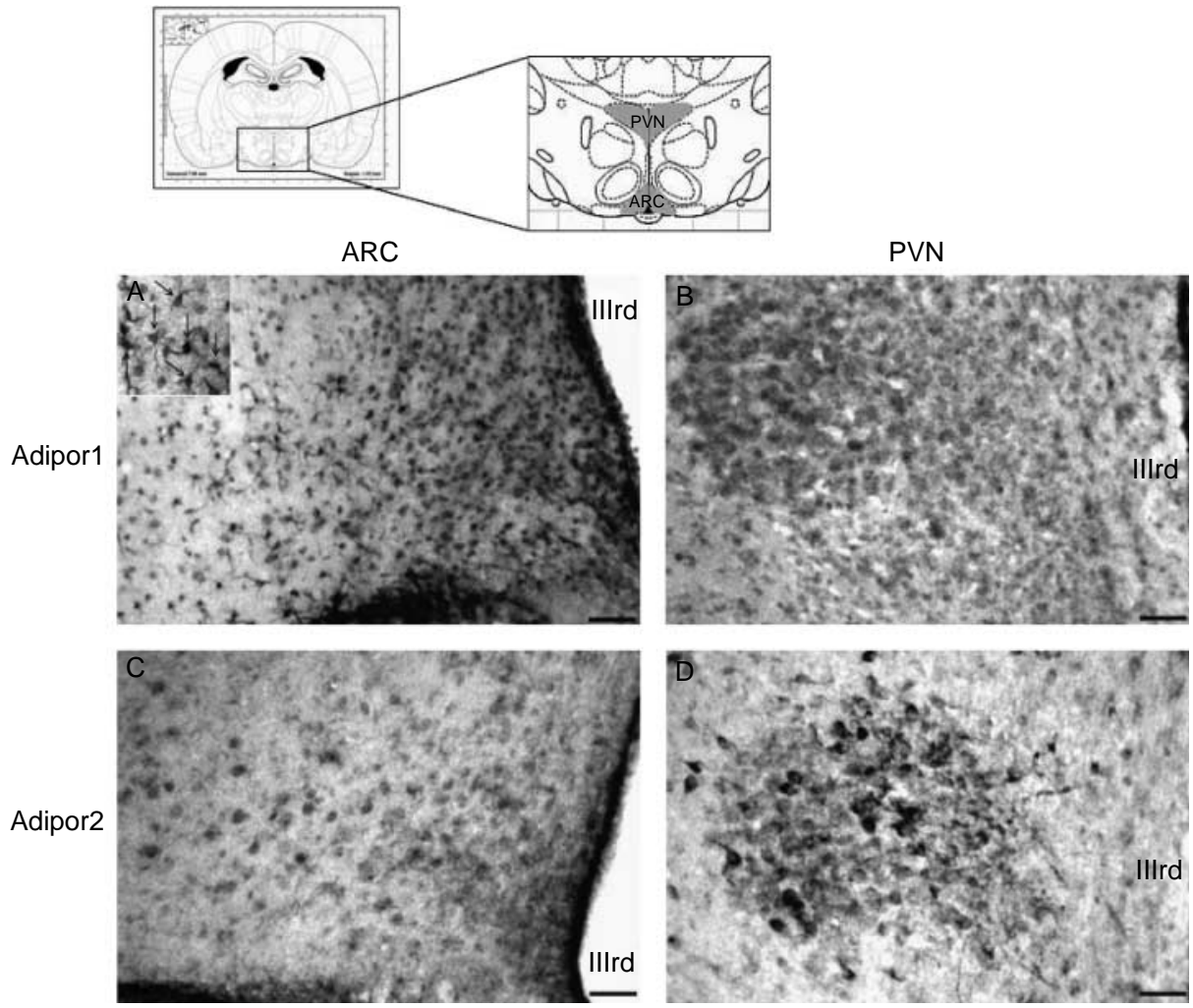

Figure 2 Hypothalamic Adipor1 (A and B) and Adipor2 (C and D) expressions, especially in rat arcuate ( $A$ and $C$ ) and paraventricular (B and D) nuclei as shown by immunohistochemistry. Schematic diagram shows location of the PVN and ARC Bregma $1.92 \mathrm{~mm}$ (25). The inset illustrates the typical stellate cytoplasm of astrocytes as designed by arrows. IIIrd, third ventricle; AdipoR, adiponectin receptors; ARC, arcuate nucleus; PVN, paraventricular nucleus. Scale bars $=50 \mu \mathrm{m}$. 
microscopy, Jena, Germany). Cross-over fluorescence could be ruled out as spectra of both fluorochromes did not overlap. Each optical section $(1 \mu \mathrm{m})$ was averaged three times. The free software ImageJ (http://rsb.info.nih.gov/ij) was used to analyze captured pictures. In the case of GFAP double IHC, figures resulted from the projection of seven successive optical sections, and in the case of NeuN, from the projection of four. Colocalization pictures were the combination of each corresponding fluorescent signals.

\section{Statistical analysis}

Results shown are the means \pm S.E.M. of at least three independent experiments. The significance of differences was estimated by ANOVA followed by Student-Neuman-Keuls test. Values of $P<0.05$ were considered as significant.

\section{Results}

\section{Characterization of rat hypothalamic Adipor1 and Adipor2}

Using primers chosen from GenBank sequences for Adipor1 and Adipor2 and flanking a region of 243 and $242 \mathrm{bp}$ respectively, RT-PCR performed on hypothalamic total RNA showed fragments with the expected size, in addition to the band corresponding to ribosomic 18S RNA (as positive control) and negative control was performed by omitting RT product (C; Fig. 1A). After cloning, the amplified fragments were sequenced and sequence analysis showed 98 and $99 \%$ identity to rat Adipor1 and rat Adipor2 respectively (data not shown). To further characterize hypothalamic Adipor1 and Adipor2, these receptors were identified by western blot analysis following SDS-PAGE using specific antibodies. Bands with expected size corresponding to Adipor1 $(42 \mathrm{kDa})$ and Adipor2 (44 kDa) were identified (Fig. 1B). The characterization was performed in 3 rat hypothalami and gel protein loading was normalized to $\beta$-tubulin (Fig. 1B).

\section{Hypothalamic localization of Adipor1}

The immunohistochemical detection of Adipor1 revealed ubiquitous expression throughout the brain regions comprised in our sections, namely cortex, hippocampus, striatum, thalamus and hypothalamus. In the hypothalamus, supraoptic, arcuate (ARC) and paraventricular (PVN) nuclei (ARC and PVN illustrated by Fig. 2A and B respectively) exhibited an important Adipor1-immunoreactivity. In ARC, the presence of immunopositive stellate cells suggested astrocytes to express Adipor1 (insert Fig. 2A). The immunostaining was abolished by incubating our sections with blocking peptides (Fig. 3A and B). The colocalization of Adipor1 and GFAP (an astroglial marker) immunoreactivities confirmed the Adipor1 expression by
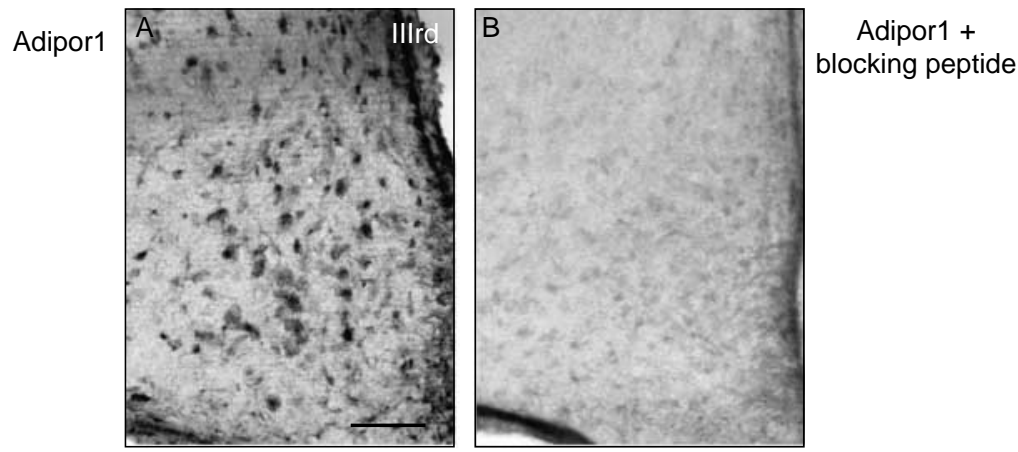

Adipor 2
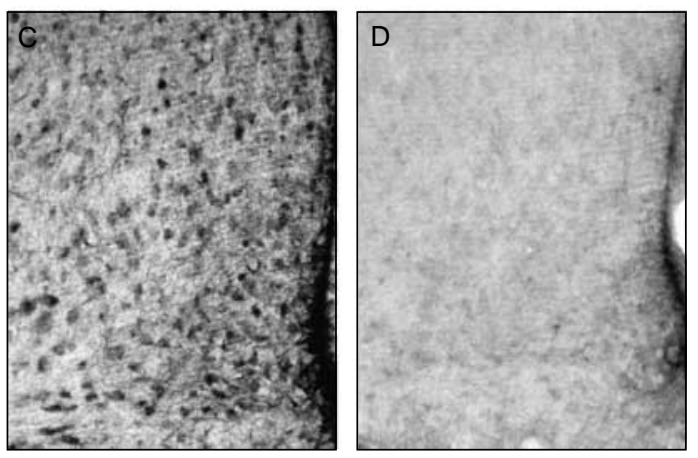

Adipor $2+$ blocking peptide

Figure 3 Control experiments. The immunohistochemical stainings of Adipor1 (A) and Adipor2 (C) in the rat ARC were abolished by incubating sections with Adipor1 (B) and Adipor2 (D) blocking peptides respectively. Adipor1, adiponectin receptor 1; Adipor2, adiponectin receptor 2 ; IIIrd, third ventricle. Scale bar $=80 \mu \mathrm{m}$. 
astrocytes (Fig. 4C). Adipor1 was also expressed by neurons, as demonstrated by the double staining combining antibodies raised against Adipor1 or NeuN, a neuronal marker (Fig. 4F). In order to investigate the phenotype of Adipor1-positive neurons, we took advantage of the existence of POMC-GFP and NPYGFP mice. This allowed us to demonstrate that GFP-tagged POMC or NPY neurons exhibited Adipor1-immunoreactivity (Figs 6A-C and 7A-D). It is noteworthy that Adipor1 colocalized with NPY-positive varicosities, namely at presynaptic sites as demonstrated by detecting synaptophysin (Fig. 8A-D). Moreover, ependymocytes (cells forming the third ventricle wall) that are negative to both markers (GFAP and
NeuN), expressed Adipor1 especially tanycytes of rat arcuate nucleus (data not shown).

\section{Hypothalamic localization of Adipor2}

The immunohistochemical analysis of hypothalamic sections indicates that brain areas expressing Adipor2 were limited to some regions such as cortex, hippocampus, amygdale, and thalamus and that Adipor2-immunofluorescent cells were less numerous than Adipor1-immunoreactive cells. In the hypothalamus, Adipor2 was localized in anterior and lateral hypothalamic $(\mathrm{LH})$ areas, perifornical region, supraoptic
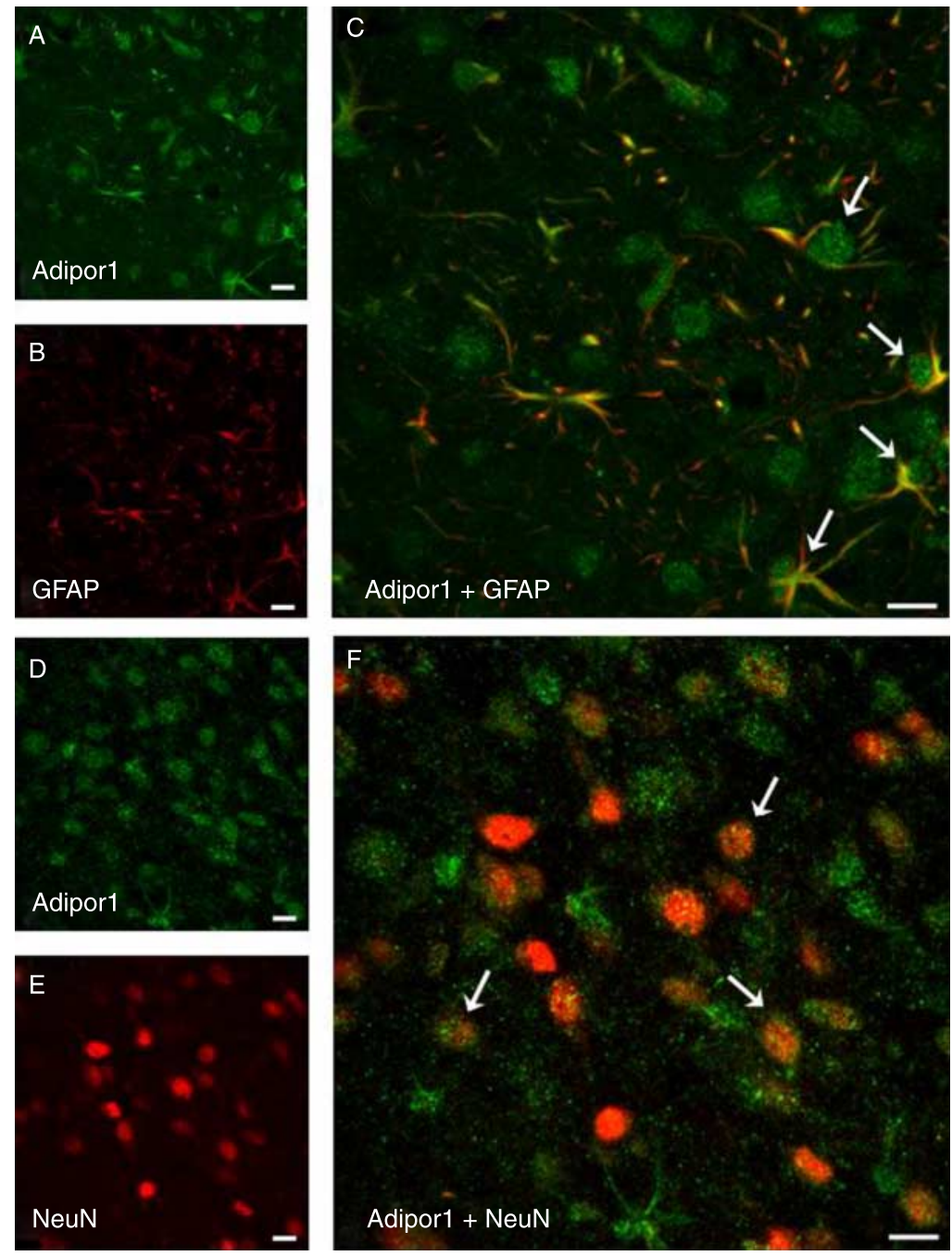

Figure 4 Characterization of cell types expressing Adipor1. Representative examples of double immunofluorescent staining for Adipor1 and GFAP, an astrocyte marker, or $\mathrm{NeuN}$, a neuronal marker ( $\mathrm{C}$ and $\mathrm{F}$ respectively) in rat arcuate nucleus. Green fluorescence reveals Adipor1 presence (A and D), while red fluorescence represents GFAP- or NeuN- immunoreactivities (B and E respectively). Arrows design some double stained cells. Adipor1, adiponectin receptor 1; GFAP, glial fibrillary acid protein; NeuN, neuronal nucleus. Scale bars: $10 \mu \mathrm{m}$. Full colour version of this figure available via http://dx.doi.org/10.1677/JOE-08-0348. 
nucleus, PVN and ARC (ARC and PVN illustrated by Fig. 2C and $\mathrm{D}$ respectively). The immunostaining was abolished by incubating our sections with blocking peptides (Fig. 3C and D) In ARC, double IHC experiments indicated that Adipor2 was astrocytic (Fig. 5A-C) but mainly neuronal (Fig. 5D-F). Furthermore, we show that POMC-GFP and NPY-GFP neurons were also positive to Adipor2 in the mouse ARC (Figs 6D-F and 7E-H). As described for Adipor1, Adipor2immunostaining was also localized in ependymocytes and tanycytes (data not shown). Control experiments were performed by omitting primary antibody or incubating sections with Adipor2 blocking peptide (data not shown; Fig. 8).

\section{Adiponectin activates hypothalamic AMPK}

To determine whether hypothalamic AdipoRs are coupled to the activation of AMPK, Wistar rats received adiponectin or placebo by ICV injection as described in materials and methods, and then hypothalamic AMPK phosphorylation was determined by western blot using specific antibodies. Adiponectin treatment significantly increased AMPK

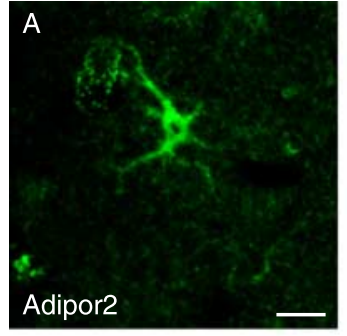

B
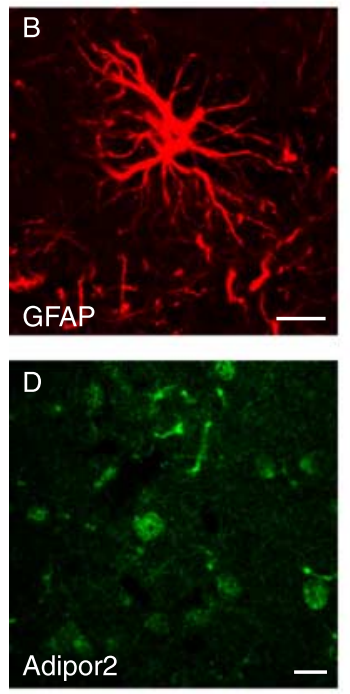

E

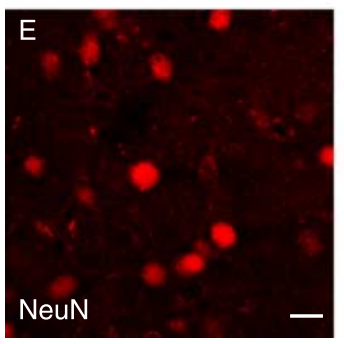

Figure 5 Characterization of cell types expressing Adipor2. Representative examples of double immunofluorescent staining for Adipor2 and GFAP, an astrocyte marker, or NeuN, a neuronal marker ( $\mathrm{C}$ and $\mathrm{F}$ respectively) in rat arcuate nucleus. Green fluorescence reveals Adipor2 presence (A and D), while red fluorescence represents GFAP- or NeuNimmunoreactivities (B and E respectively). Arrows design some double stained cells. Adipor2, adiponectin receptor 2; GFAP, glial fibrillary acid protein; NeuN, neuronal nucleus. Scalebars: $10 \mu \mathrm{m}$. Full colour version of this figure available via http://dx.doi.org/10.1677/JOE-08-0348. 
phosphorylation by about $80 \%(P<0 \cdot 05$; Fig. 9$)$. Then, we attempted to demonstrate that the activation of AMPK was due to a direct effect of adiponectin by measuring in vitro phosphorylation of AMPK in response to adiponectin stimulation. Rat hypothalamus total membrane extracts were incubated in the presence or absence of adiponectin and then AMPK phosphorylation was measured by western blot as described above. In vitro, adiponectin significantly stimulates AMPK phosphorylation when compared with the control by about $92 \%(P<0 \cdot 05$; Fig. 10).
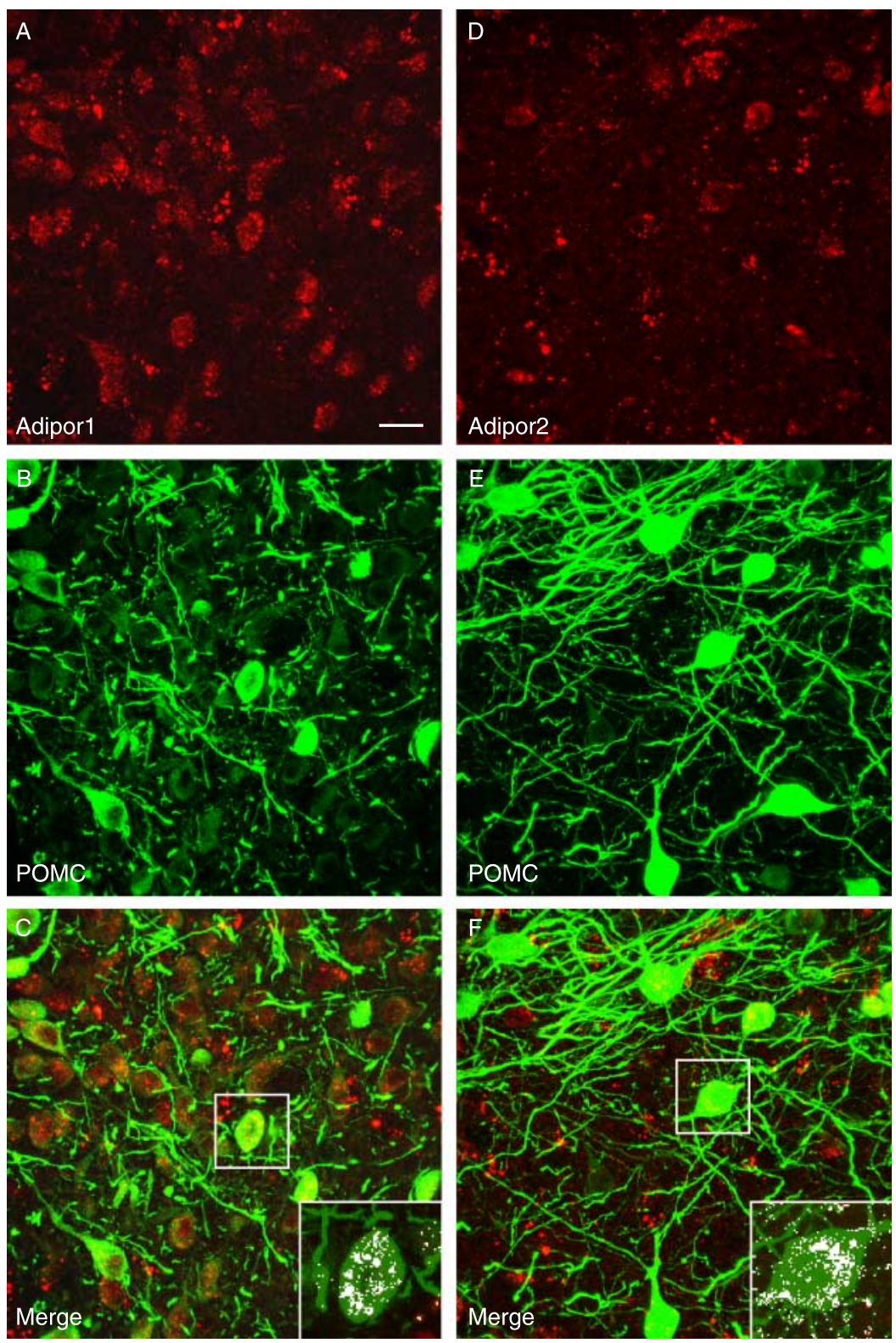

Figure 6 Fluorescent immunohistochemical detection of Adipor1 or Adipor2 in the ARC of POMC-GFP mice by confocal laser scanning microscopy. Adipor1 (A-C) and Adipor2 (D-F) -immunofluorescence is detected in POMC-GFP tagged neurons. Colocalization appears as yellow on the projection of three successive 1- $\mu \mathrm{m}$-thick optical sections (large photographs) or as white pixels in detailed $1-\mu \mathrm{m}$-thick optical section (insets $\mathrm{C}$ and $\mathrm{F}$ ). Bar represents $30 \mu \mathrm{m}$. Full colour version of this figure available via http://dx.doi.org/10.1677/ JOE-08-0348. 

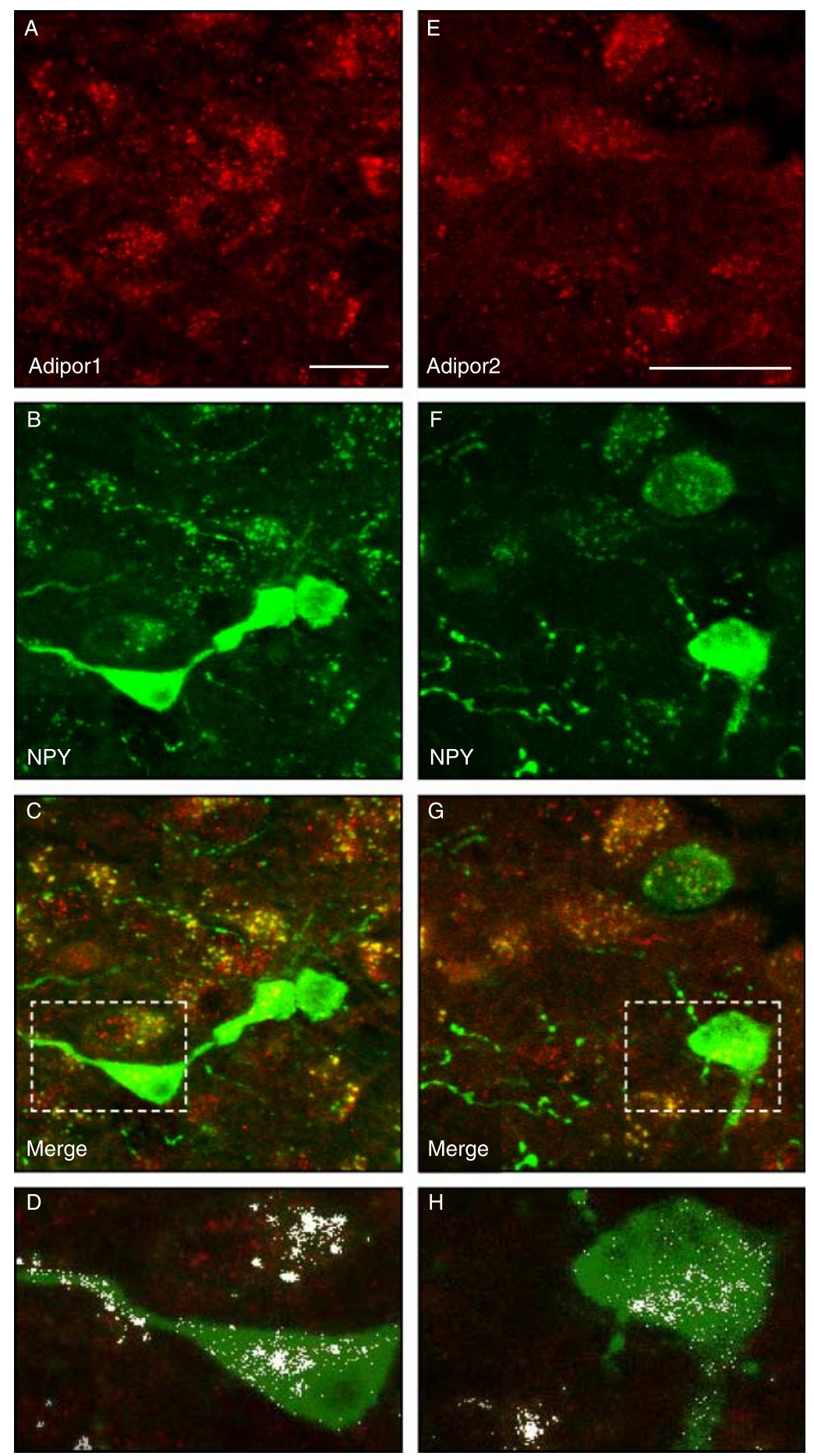

Figure 7 Fluorescent immunohistochemical detection of Adipor1 or Adipor2 in the ARC of NPY-GFP mice by confocal laser scanning microscopy. Adipor1 (A-D) and Adipor2 $(\mathrm{E}-\mathrm{H})$-immunofluorescence is detected in NPY-GFP tagged neurons.

Colocalization appears as yellow on the projection of three successive 1 - $\mu \mathrm{m}$-thick optical sections (large photographs $\mathrm{A}-\mathrm{C}$ and $\mathrm{E}-\mathrm{G}$ ), or as white pixels in detailed 1- $\mu \mathrm{m}$ thick optical section $(\mathrm{D}$ and $\mathrm{H}$ ). Bars represent $15 \mu \mathrm{m}$. Full colour version of this figure available via http://dx.doi.org/10.1677/JOE-08-0348. 

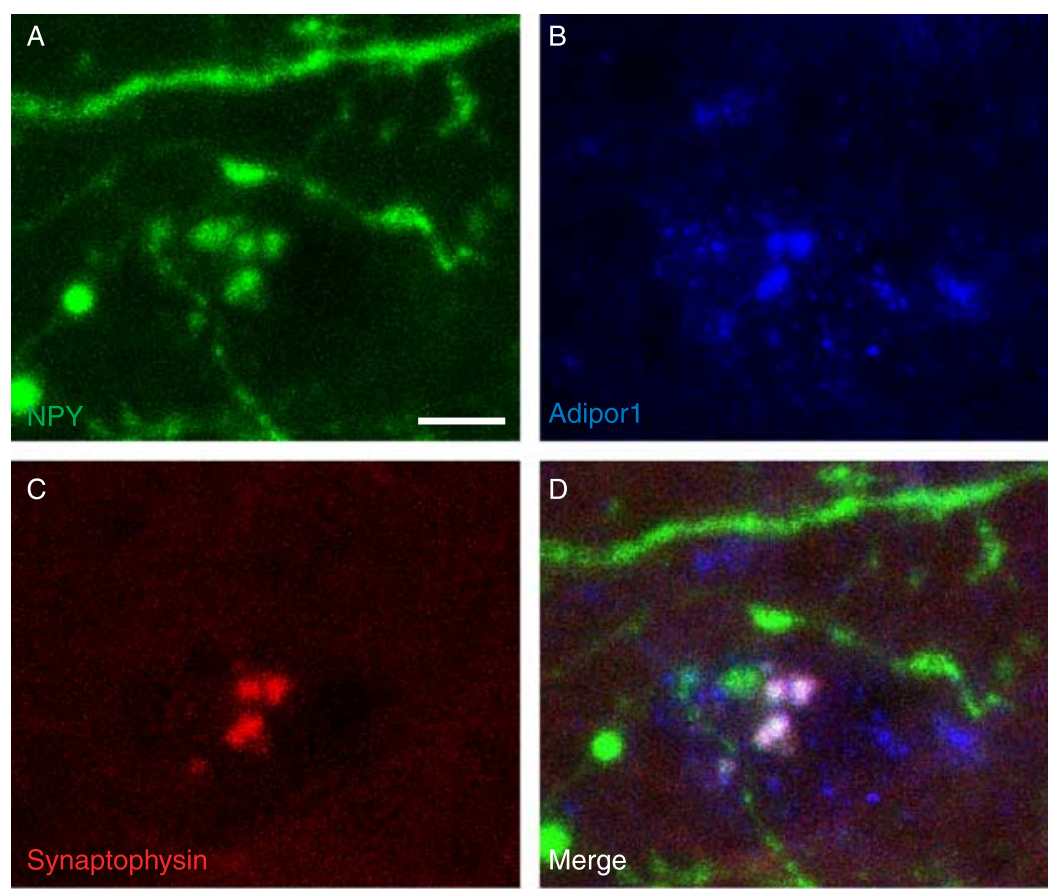

Figure 8 Fluorescent immunohistochemical detection of Adipor1 and synaptophysin in a NPY-GFP neuron by confocal laser scanning microscopy. Detection of a NPY-GFP neuron in the ARC (green, A). Immunodetection of Adipor1 (blue, B) and synaptophysin (red, C) on the same focal plane. Triple colocalization appears as white (D) on the same optical section. Adipor1 appears as clusters in NPY-GFP neurons that colocalize with synaptophysin. Bar represents $10 \mu \mathrm{m}$. Full colour version of this figure available via http:// dx.doi.org/10.1677/JOE-08-0348.

\section{Discussion}

Adiponectin receptors (Adipor1 and Adipor2) have been identified at the mRNA level in various tissues including brain in mice although their expressions were mainly localized in muscle and liver (Yamauchi et al. 2003). Recently, the presence of AdipoRs has been observed by IHC in rodent and human hypothalamus (Kos et al. 2007, Kubota et al. 2007, Coope et al. 2008). The hypothalamic expression of AdipoRs may strengthen the potential role of adiponectin in controlling energy homeostasis as already suggested by others (Qi et al. 2004, Kubota et al. 2007). However, these studies did not identify the specific brain cells and hypothalamic areas expressing AdipoRs. In the present work, we sought to characterize adiponectin receptors in rat hypothalamic nuclei and to demonstrate that adiponectin activates downstream signaling of AdipoRs as mirrored by the AMPK phosphorylation.

First we showed that Adipor1 and Adipor2 were localized in the rat hypothalamus, a structure containing areas involved in the control of feeding such as LH, PVN and ARC. Adipor1 was expressed throughout cerebral regions in both glial cells and neurons, thus its expression appeared ubiquitous. Adipor2 expression seems to be less extended and particularly located in the hypothalamus nuclei and preferentially in neurons. These

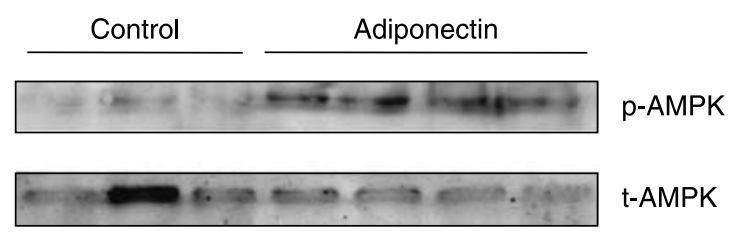



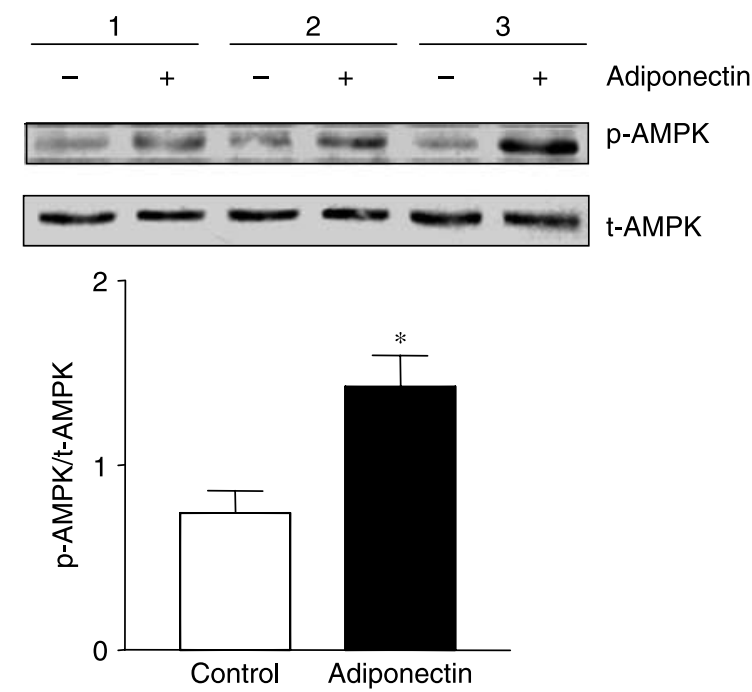

Figure 10 In vitro AMPK phosphorylation in response to adiponectin. Three hypothalamus homogenates $(1-3)$ were incubated in the absence $(-)$ or presence $(+)$ of adiponectin and AMPK phosphorylation measured by western blot using specific antibodies (upper panel). AMPK phosphorylation was normalized to total AMPK (upper panel). The ratio of phosphorylated AMPK/totalAMPK is shown in lower panel. Results were expressed as mean \pm S.E.M $(n=3)$ and * indicates $P<0 \cdot 05$.

observations add a neuro-anatomical support to the concept that adiponectin and its receptors could be involved in the hypothalamic regulation of energy homeostasis in rat. Indeed, ARC contains both orexigenic (notably producing NPY) and anorexigenic (expressing POMC) neurons that are sensitive to metabolic and hormonal changes, and also expresses receptors for anorexigenic hormones: insulin (IR) and leptin $(\mathrm{ObRb}$; Hâkansson et al. 1998, Obici et al. 2002). The location of Adipor1 and Adipor2 in the same neuronal populations suggests a possible link between these receptors and NPY and POMC expression. Such an interaction was already suggested by Kubota et al. (2007) who reported an increased expression of POMC and reduced expression of NPY in the adiponectin $-/-$ mice. Moreover, our results showed the presence of Adipor1 on NPY varicosities indicating its plausible role in NPY release in the ARC.

Secondly, we attempted to demonstrate the functionality of hypothalamic AdipoRs following adiponectin ICV treatment in rat. Indeed, Adipor1 and Adipor2 have been recently differently involved in signaling pathways such as AMPK/glucose metabolism and PPAR $\alpha$ /lipid metabolism in peripheral tissues (Yamauchi et al. 2002, Bjursell et al. 2007). However, in the hypothalamus, Adipor1 and Adipor2 signaling pathways are not yet clearly elucidated except the AMPK stimulation by adiponectin through Adipor1 in mice (Kubota et al. 2007). In our experiment, adiponectin clearly increased AMPK phosphorylation in rat hypothalamus. Adiponectin-dependent activation of AMPK was also confirmed by an in vitro phosphorylation test suggesting that AdipoRs/AMPK signaling pathways may be activated in rat hypothalamus by adiponectin as in peripheral tissues (Tomas et al. 2002, Huypens et al. 2005). The physiological relevance of the central adiponectin action is reinforced by the fact that low molecular forms of adiponectin can cross the brain blood barrier (BBB) and are also found in human cerebrospinal fluid (Kuminski et al. 2007). Furthermore, systemic adiponectin may penetrate the arcuate nucleus. Indeed, it has been demonstrated that arcuate neurons project to the median eminence, a circumventricular organ, and that the ventromedial arcuate nucleus lacks endothelial barrier antigen and transferrin receptors, two BBB markers (Norsted et al. 2008). The adiponectin peripheral and central effects contrast with other hormones such as ghrelin that activates AMPK in the hypothalamus but inhibits it in peripheral tissues or as leptin that inhibits AMPK in the hypothalamus but activates it in peripheral cells (Minokoshi et al. 2002, Steinberg et al. 2003, Kola et al. 2005). Thus, an activation of AMPK in the hypothalamus is generally associated with the action of orexigenic hormones and inversely an inhibition with anorexigenic ones, however, the role of adiponectin on food intake control is not yet clearly established. Different studies showed no effect of this hormone following acute or short term administrations (Masaki et al. 2003, Qi et al. 2004) and two controversial reports showed orexigenic (Kubota et al. 2007) or anorexigenic (Coope et al. 2008) actions in rodents. Our study demonstrates the colocalization of Adipor1/Adipor2 with both POMC and NPY neurons in arcuate hypothalamic nucleus. It is thus tempting to speculate that adiponectin may modulate the production of these neuropeptides according to the variations of energetic status of the animal.

In summary, we show that in rat hypothalamus, Adipor1 is distributed in the neurons and astrocytes whereas Adipor2 is mainly neuronal. Furthermore, Adipor1 and Adipor2 are expressed in POMC and NPY neurons in arcuate hypothalamic nucleus. Finally, we demonstrate that adiponectin activates AMPK phosphorylation in hypothalamus. Taken together, our data clearly indicate a potential role of adiponectin in the control of energy homeostasis at the hypothalamic level.

\section{Declaration of interest}

The authors declare that there is no conflict of interest that could be perceived as prejudicing the impartiality of the research reported.

\section{Funding}

This research did not receive any specific grant from any funding agency in the public, commercial or not-for-profit sector.

\section{Acknowledgements}

We acknowledge Dr Jeffrey M Friedman for the GFP-mice and Joël Lefêbvre for the care and maintenance of the rodents.

Journal of Endocrinology (2009) 200, 93-105 


\section{References}

Andersson U, Filipsson K, Abbott CR, Woods A, Smith K, Bloom SR, Carling D \& Small C 2004 AMP-activated protein kinase plays a role in the control of food intake. Journal of Biological Chemistry 279 12005-12008.

Benomar Y, Roy AF, Aubourg A, Djiane J \& Taouis M 2005 Cross downregulation of leptin and insulin receptor expression and signalling in a human neuronal cell line. Biochemical Journal 388 929-939.

Benomar Y, Naour N, Aubourg A, Bailleux V, Gertler A, Djiane J, Guerre-Millo M \& Taouis M 2006 Insulin and leptin induce Glut 4 plasma membrane translocation and glucose uptake in a human neuronal cell line by a PI 3-kinase dependent mechanism. Endocrinology 147 2550-2556.

Berg AH, Combs TP \& Scherer PE 2002 ACRP30/adiponectin: an adipokine regulating glucose and lipid metabolism. Trends in Endocrinology and Metabolism 13 84-89.

Berner HS, Lyngstadaas SP, Spahr A, Monjo M, Thommesen L, Drevon CA, Syversen U \& Reseland JE 2004 Adiponectin and its receptors are expressed in bone-forming cells. Bone 35 842-849.

Bjursell M, Ahnmark A, Bohlooly YM, William-Olsson L, Rhedin M, Peng XR, Ploj K, Gerdin AK, Arnerup G, Elmgren A et al. 2007 Opposing effects of adiponectin receptors 1 and 2 on energy metabolism. Diabetes 56 583-593.

Carling D 2005 AMP-activated protein kinase: balancing the scales. Biochimie 87 87-91.

Coope A, Milanski M, Araujo P, Tambascia M, Saad M, Genoleze B \& Velloso L 2008 AdipoR1 mediates the anorexigenic and insulin/leptin-like actions of adiponectine in the hypothalamus. FEBS Letters $\mathbf{5 8 2}$ 1471-1476.

Dai MH, Xia T, Zhang GD, Chen XD, Gan L, Feng SQ, Qiu H, Peng Y \& Yang ZQ 2006 Cloning, expression and chromosome localization of porcine adiponectin and adiponectin receptors genes. Domestic Animal Endocrinology 30 117-125.

Ding ST, Liu BH \& Ko YH 2004 Cloning and expression of porcine adiponectin and adiponectin receptor 1 and 2 genes in pigs. Journal of Animal Science 82 3262-3174.

Ferezou-Viala J, Roy AF, Serougne C, Gripois D, Parquet M, Bailleux V, Gertler A, Delplanque B, Djiane J, Riottot M et al. 2007 Long-term consequences of maternal high-fat feeding on hypothalamic leptin sensitivity and diet-induced obesity in the offspring. American Journal of Physiology. Regulatory, Integrative and Comparative Physiology 293 R1056-R1062.

Gil-Campos M, Canete R \& Gil A 2004 Adiponectin, the missing link in insulin resistance and obesity. Clinical Nutrition 23 963-974.

Hâkansson ML, Brown H, Ghilardi N, Skoda RC \& Meister B 1998 Leptin receptor immunoreactivity in chemically defined target neurons of the hypothalamus. Journal of Neuroscience 18 559-572.

Hawley SA, Boudeau J, Reid JL, Mustard KJ, Udd L, Makela TP, Alessi DR \& Hardie DG 2003 Complexes between the LKB1 tumor suppressor, STRAD $\alpha / \beta$ and MO25 $\alpha / \beta$ are upstream kinases in the AMP-activated protein kinase cascade. Journal of Biology 228.

Hu ZY, Cha SH, Chohnan S \& Lane MD 2003 Hypothalamic malonyl-CoA as a mediator of feeding behaviour. PNAS 100 12624-12629.

Huypens P, Moens K, Heimberg H, Ling ZD, Pipeleers D \& Van de Casteele M 2005 Adiponectin-mediated stimulation of AMP-activated protein kinase (AMPK) in pancreatic beta cells. Life Sciences 77 1273-1282.

Kadowaki T \& Yamauchi T 2005 Adiponectin and adiponectin receptors. Endocrine Reviews 26 439-451.

Kadowaki T, Yamauchi T \& Kubota N 2008 The physiological and pathophysiological role of adiponectin and adiponectin receptors in the peripheral tissues and CNS. FEBS Letters 582 74-80.

Kharroubi H, Rasschaert J, Eizirik DL \& Cnop M 2003 Expression of adiponectin receptors in pancreatic beta cells. Biochemical and Biophysical Research Communications 312 1118-1122.

Kim M \& Lee KU 2005 Role of hypothalamic 5'-AMP-activated protein kinase in the regulation of food intake and energy homeostasis. Journal of Molecular Medicine 83 514-520.

Kola B, Hubina E, Tucci SA, Kirkham TC, Garcia EA, Mitchell SE, Williams LM, Hawley SA, Hardie DG, Grossman AB et al. 2005 Cannabinoids and ghrelin have both central and peripheral metabolic and cardia effects via AMP-activated protein kinase. Journal of Biological Chemistry $\mathbf{2 8 0}$ 25196-25201.

Kos K, Harte AL, da Silva NF, Tontchev A, Chalakov G, James S, Snead DR, Hoggart B, O'hare JP, McTernan PG et al. 2007 Adiponectin and resistin in human cerebrospinal fluid and expression of adiponectin receptors in the human hypothalamus. Journal of Clinical Endocrinology and Metabolism 92 1129-1136.

Kubota N, Yano W, Kubota T, Yamauchi T, Itoh S, Kumagai H, Kozono H, Takamoto I, Okamoto S, Shiuchi Tet al. 2007 Adiponectin stimulates AMPactivated protein kinase in the hypothalamus and increases food intake. Cell Metabolism 6 55-68.

Kuminski CM, McTernan PG, Schraw T, Kos K, O’Hare JP, Ahima R, Kumar S \& Scherer PE 2007 Adiponectin complexes in human cerebrospinal fluid: distinct complex distribution from serum. Diabetologia 50 634-642.

Lane MD, Hu Z, Cha SH, Dai Y, Wolfgang M \& Sidhaye A 2005 Role of malonyl-CoA in the hypothalamic control of food intake and energy expenditure. Biochemical Society Transactions 33 1063-1067.

Long YC \& Zierath JR 2006 AMP-activated protein kinase signalling in metabolic regulation. Journal of Clinical Investigation 116 1776-1783.

Mao XM, Kikani CK, Riojas RA, Langlais P, Wang LX, Ramos FJ, Fang QC, Christ-Roberts CY, Hong JY, Kim R-Y et al. 2006 APPL1 binds to adiponectin receptors and mediates adiponectin signalling and function. Nature Cell Biology 8 516-536.

Masaki T, Chiba S, Yasuda T, Tsubone T, Kakuma T, Shimonura I, Funahashi T, Matsuzawa Y \& Yoshimatsu H 2003 Peripheral, but not central, administration of adiponectine reduces visceral adiposity and upregulates the expression of uncoupling protein in agouti yellow (Ay/a) obese mice. Diabetes 52 2266-2273.

Minokoshi Y, Kim YB, Peroni OD, Fryer LG, Muller C, Carling D \& Kahn BB 2002 Leptin stimulates fatty-acid oxidation by activating AMP-activated protein kinase. Nature 415 339-343.

Minokoshi Y, Alquier T, Furukawa N, Kim YB, Lee A, Xue BZ, MuJ, Foufelle F, Ferre P, Birnbaum MJ et al. 2004 AMP-kinase regulates food intake by responding to hormonal and nutrient signals in the hypothalamus. Nature $\mathbf{4 2 8}$ $569-574$.

Norsted E, Gomuç B \& Meister B 2008 Protein components of the blood-brain barrier (BBB) in the mediobasal hypothalamus. Journal of Chemical Neuroanatomy 36 107-121.

Obici S, Feng Z, Karkanias G, Baskin DG \& Rossetti L 2002 Decreasing hypothalamic insulin receptors causes hyperphagia and insulin resistance in rats. Nature Neuroscience 5 566-572.

Paxinos G \& Watson C 2005 The Rat Brain in Stereotaxic Coordinates. edn 5, San Diego, CA: Elsevier Academic Press.

Pineiro R, Iglesias MJ, Gallego R, Raghay K, Eiras S, Rubio J, Dieguez C, Gualillo O, Gonzalez-Juanatey JR \& Lago F 2005 Adiponectin is synthesized and secreted by human and murine cardiomyocytes. FEBS Letters 579 5163-5169.

Pinto S, Roseberry AG, Liu H, Diano S, Shanabrough M, Cai X, Friedman JM \& Horvath TL 2004 Rapid rewiring of arcuate nucleus feeding circuits by leptin. Science 304 110-115.

Qi Y, Takahashi N, Hileman SM, Patel HR, Berg AH, Pajvani UB, Scherer PE \& Ahima RS 2004 Adiponectin acts in the brain to decrease body weight. Nature Medicine 10 524-529.

Steinberg GR, Rush JW \& Dyck DJ 2003 AMPK expression and phosphorylation are increased in rodent muscle after chronic leptin treatment. American Journal of Physiology. Endocrinology and Metabolism 284 E648-E654.

Tomas E, Tsao TS, Saha AK, Murrey HE, Zhang CcC, Itani SI, Lodish HF \& Ruderman NB 2002 Enhanced muscle fat oxidation and glucose transport by ACRP30 globular domain: acetyl-CoA carboxylase inhibition and AMP-activated protein kinase activation. PNAS 99 16309-16313.

Wolf G 2006 The regulation of food intake by hypothalamic malonyl-coenzyme A: the MalCoA hypothesis. Nutrition Reviews 64 379-383.

Yamauchi T, Kamon J, Minokoshi Y, Ito Y, Waki H, Uchida S, Yamashita S, Noda M, Kita S, Ueki K et al. 2002 Adiponectin stimulates glucose utilization and fatty-acid oxidation by activating AMP-activated protein kinase. Nature Medicine 8 1288-1295. 
Yamauchi T, Kamon J, Ito Y, Tsuchida A, Yokomizo T, Kita S, Sugiyama T, Miyagishi M, Hara K, Tsunoda M et al. 2003 Cloning of adiponectin receptors that mediate antidiabetic metabolic effects. Nature $\mathbf{4 2 3} 762-779$

Yamauchi T, Nio Y, Maki T, Kobayashi M, Takazawa T, Iwabu M, OkadaIwabu M, Kawamoto S, Kubota N, Kubota T et al. 2007 Targeted disruption of AdipoR1 and AdipoR2 causes abrogation of adiponectin binding and metabolic actions. Nature Medicine 13 332-339.

Yoon MJ, Lee GY, Chung JJ, Ahn YH, Hong SH \& Kim JB 2006 Adiponectin increases fatty acid oxidation in skeletal muscle cells by sequential activation of AMP-activated protein kinase, p38 mitogenactivated protein kinase, and peroxisome proliferator-activated receptor. Diabetes 55 2562-2570.
Zhao W, Chen H, Xu H, Moore E, Meiri N, Quon MJ \& Alkon DL 1999 Brain insulin receptors and spatial memory. Correlated changes in gene expression, tyrosine phosphorylation, and signaling molecules in the hippocampus of water maze trained rats. Journal of Biological Chemistry 274 34893-34902.

Received in final form 14 October 2008

Accepted 21 October 2008

Made available online as an Accepted Preprint 24 October 2008 